\title{
Transport Protein Gene
}

National Cancer Institute

\section{Source}

National Cancer Institute. Transport Protein Gene. NCI Thesaurus. Code C28533.

Transport Protein Genes encode a diverse group of proteins that function as carriers of lig ands through solubility barriers such as aqueous body fluids or in active transport across cell membranes. (NCl) 